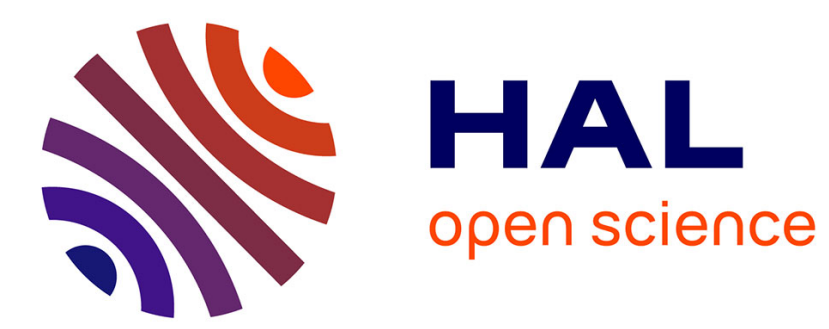

\title{
OPTICAL BISTABILITY IN ACTIVE DEVICES
}

Hitoshi Kawaguchi

\section{To cite this version:}

Hitoshi Kawaguchi. OPTICAL BISTABILITY IN ACTIVE DEVICES. Journal de Physique Colloques, 1988, 49 (C2), pp.C2-63-C2-68. 10.1051/jphyscol:1988214 . jpa-00227631

\section{HAL Id: jpa-00227631 https://hal.science/jpa-00227631}

Submitted on 1 Jan 1988

HAL is a multi-disciplinary open access archive for the deposit and dissemination of scientific research documents, whether they are published or not. The documents may come from teaching and research institutions in France or abroad, or from public or private research centers.
L'archive ouverte pluridisciplinaire HAL, est destinée au dépôt et à la diffusion de documents scientifiques de niveau recherche, publiés ou non, émanant des établissements d'enseignement et de recherche français ou étrangers, des laboratoires publics ou privés. 


\title{
OPTICAL BISTABILITY IN ACTIVE DEVICES
}

\author{
Hitoshi KAWAGUCHI \\ NTT Opto-Electronics Laboratories, 3-1, Morinosato, Wakamiya, \\ Atsugi-shi, Kanagawa, 243-01, Japan
}

\begin{abstract}
Recent progress in the study of both absorptive and dispersive bistability in semiconductor lasers is reviewed. Inhomogeneously excited semiconductor lasers as an absorptive case and resonant type laser diode amplifiers as a dispersive case, are described.
\end{abstract}

\section{Introduction}

Recent progress in the study of both absorptive and dispersive bistability in laser diodes (LDS) is reviewed /1/. The most distinctive feature of bistable LDs is that they have optical gain. optical gain results in advantages such as low switching optical power, high on-OFF ratio, and large fan-out.

The first stage in the study of optical bistable LDs started in 1964 with the tandem-type LD proposed by Lasher /2/. Based upon the advanced semiconductor laser technology developed for optical fiber communications, the second stage of bistable LD study began in 1981 by Kawaguchi and Iwane/3/ and Harder et al: /3/. They reported remarkable bistable characteristics in InP/InGaAsP lasers and GaAs/AIGaAs lasers, respectively.

Since then, various types of bistable LDs have been reported as 1 isted in Table 1 . Bistability can be seen in ON-OFF of laser oscillation/2-4/, optical gain change in resonant type LD amplifiers /5/, polarization /6/, transverse mode /7,8/, lasing wavelength $/ 9 /$ as well as locked and unlocked state in. injection locking systems /10/. Details are described in Reference /11/.

Applications to photonic switching and optical fiber communications have already been investigated. Using tandem-type laser diodes as optical memories, an optical time-division switching system was developed by suzuki et al./12/. Webb has studied the use of a bistable LD amplifter as a clocked decision gate, and shown that all-optical regeneration using such a gate is feasible /13/.

\section{Absorptive bistability}

Inhomogeneousiy excited LDs such as tandem type LDs show bistabijity in the current-light output curve and optical input-output curve. This is because the region where a carrier is not injected acts as a saturable absorber.

Sometimes self-pulsing as well as bistability are present in tandem-type LDs. These depend on the carrier lifetime distribution along a laser cavity/14/. A 
Table 1. Bistable semiconductor lasers

\begin{tabular}{|c|c|c|c|c|}
\hline Switching & LD Structure & Principle & Characteristics & References \\
\hline $\begin{array}{l}\text { laser oscillotion } \\
\text { ON / OFF }\end{array}$ & $\begin{array}{l}\text { inhomogeneous excitation } \\
e \cdot g \cdot \text { tondem type } \\
(F P, D F B)\end{array}$ & $\begin{array}{l}\text { soturable } \\
\text { absorption }\end{array}$ & $\begin{array}{l}\text { proposal } \\
\text { demonstration } \\
\tau: \text { sub-ns } \\
P:<I \mu W\end{array}$ & $\begin{array}{l}\text { Lasher } \\
\text { Kawaguchi et al./Lau et al. } \\
\text { Tomita ef al. } \\
\text { Suzuki et al. }\end{array}$ \\
\hline gain & $\begin{array}{l}\text { resonont type } \\
\text { LD amplifier } \\
\text { (FP, DFB ) }\end{array}$ & $\begin{array}{c}\text { nonlinear refroctive } \\
\text { index }\end{array}$ & $\begin{array}{l}\text { proposal } \\
\text { multiple bistability } \\
P:<I \mu W \\
\text { 'NOT'(two inputs) } \\
\text { 'NOT'(reflection) } \\
\end{array}$ & $\begin{array}{l}\text { Ohtsuka et al. } \\
\text { Kawaguchi } \\
\text { Adams et al. } \\
\text { Kawaguchi } \\
\text { Adams et al. }\end{array}$ \\
\hline \multirow{2}{*}{ polarization } & TM light injection & $\begin{array}{l}\text { nonlinear gain / } \\
\text { refractive index }\end{array}$ & $\tau: \begin{array}{l}\text { ON } 200 \text { ps } \\
\text { OFF 430ps }\end{array}$ & Mori et al. \\
\hline & TM/TE oscillotion LD & $\begin{array}{l}\text { temperature } \\
\text { dependent goin }\end{array}$ & & Chen et al. \\
\hline transeverse mode & twin-stripe & mode-gain change & $\begin{array}{l}\tau:<250 \text { ps } \\
P: \sim \text { sub-pJ }\end{array}$ & Maclean et al. \\
\hline lasing wavelength & LD with external covity & mode hoping & & Glas et al. \\
\hline locked/unlocked & injection locking & $\begin{array}{c}\text { nonlinear refractive } \\
\text { index }\end{array}$ & & Kawoguchi \\
\hline
\end{tabular}

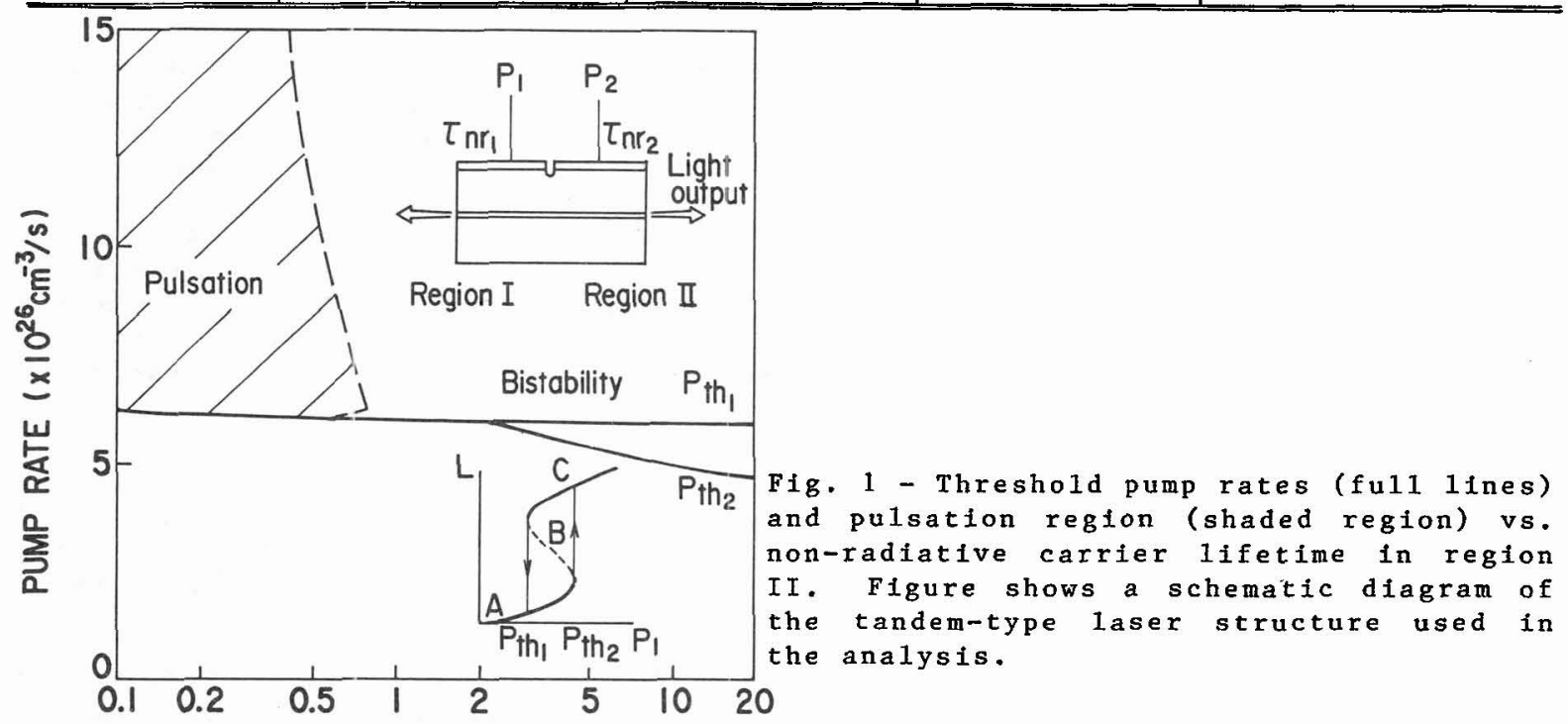

NONRADIATIVE LIFETIME IN REGION II $\tau_{\mathrm{nr}_{2}}$ (ns)

electrode was divided into two parts along the laser cavity, and drive currents were injected separately into the.divided parts as shown in Fig. 1. The case where the two parts of the active region were given different carrier recombination rates was considered using different non-radiative carrier lifetimes for each region. The threshold pump rate and output stability as a function of the nonradiative carrier lifetime in region 2 , $\tau_{\text {nr }}$, are shown in Fig. 1 . The solid lines indicate the threshold pump rates. When $\tau_{n r 2} 1 s$ longer than 2 ns, the laser has two threshold pump rates, $P$ and $P$, nidepending on the initial conditions. These bistable characteristics can be attributed to the fact that the active layer of region 2 acts as a saturable absorber. When the nonradiative carrier lifetime is shorter than $2 \mathrm{~ns}$, the laser has only one threshold pump rate: The shaded region represents the pulsation region in the figure. When the nonradiative carrier lifetime is shorter than $0.5 \mathrm{~ns}$, self-pulsation occurs over a 


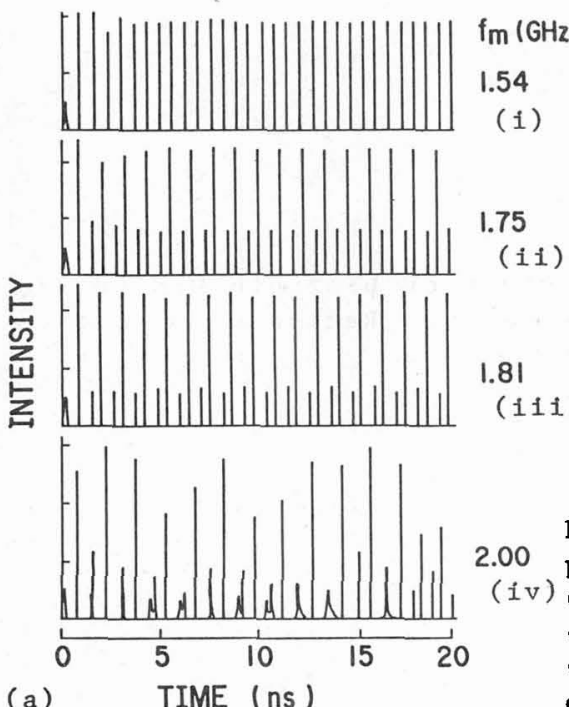

(a)

TIME (ns)

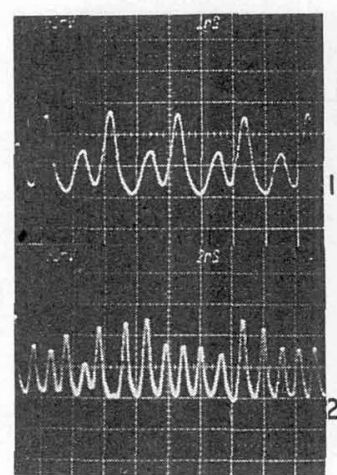

(b)
Temporal plot

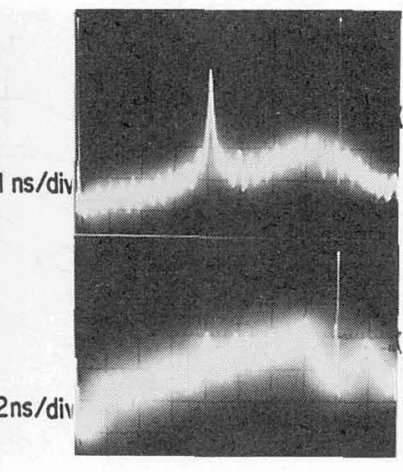

Spectrum (i) $f m=1 \mathrm{GHz}$

$f_{R}=875 \mathrm{MHz}$

(Period 2)

ii) $f_{m}=1 \mathrm{GHz}$

$f_{R}=820 \mathrm{MHz}$

(Chaotic)

Fig. 2 - (a) Calculated output response of seifpulsating laser for sinusoidal current modulation. (i) Perfod 1, (i1) period 2, (iii) period 4, and (iv) chaotic.

(b) Observed output response. (i) period 2 and (ii) chaotic.

wide range from just above the laser threshold to a very high excitation level. Due to their nonlinearity, semiconductor lasers exhibit interesting characteristics when the current and carrier lifetime distribution are changed along the laser cavity.

One example of optical chaos in LDs is briefly discussed. We considered the laser which shows self-pulsation because the carrier lifetime of reglon 2 is short . Furthermore, the pump rate in region $I$, is modulated by sinusoidal RF current superimposed on the DC bias current. This nonitnear laser system shows chaotic behavior through period-doubling bifurcations with increasing moduation frequency as seen in Fig. 2(a) /14/. At $1.54 \mathrm{GHz}$, the laser showed sustained pulse oscillation with the modulation frequency. The first subharmonic appeared at 1.75 GHz. At $1.81 \mathrm{GHz}$, period 4 oscillation was obtained. Furthermore, chaotic outputs were seen at above $2 \mathrm{GHz}$.

These characteristics were also observed in the experiment /15/. Experimental waveforms and spectra from a GaAlAs LD are shown in Fig. 2(b). By increasing the difference between the resonance frequency, ${ }_{R}$, and modulation frequency, $f_{m}$, period 2 and chaotic oscillation were observed.

When carrier lifetime is about the same over the whole laser cavity, tandem type LDs show bistable output characteristics. The InGaAsP distributed-feedback laser structure operating at $1.55 \mu \mathrm{m}$ is shown in Fig.3. The p-type electrode was divided into three parts, and the resistance between the p-type electrodes was within a few hundred $\Omega$. Thus, the divided regions can be excited independently through the electrodes. If I is set at zero or a low value, reglon 1 acts as a saturable absorber. It is then possible to obtain bistable characteristics in both the current-light output and optical input-output curves.

A typical measured current-1ight output curve is shown in Fig. 4 (a). A noticeable hysteresis loop is seen in the curve. The current range of bistability decreases with increasing in the current injected into the saturable absorber. The current can optimize the bistable current range.

When the bias current is set at just below the turn-off throshold, the optical input-output curve exhibits bistability resulting from an injection of optical power into the saturable abosrber as shown in Fig. 4(b). The bias current values are indicated by the closed circles (1) to (3) in Fig. 4(a). An increase in the bias current markedly increases the input optical power range of bistability. When the bias current is in the current range of bistability, the bistable laser 


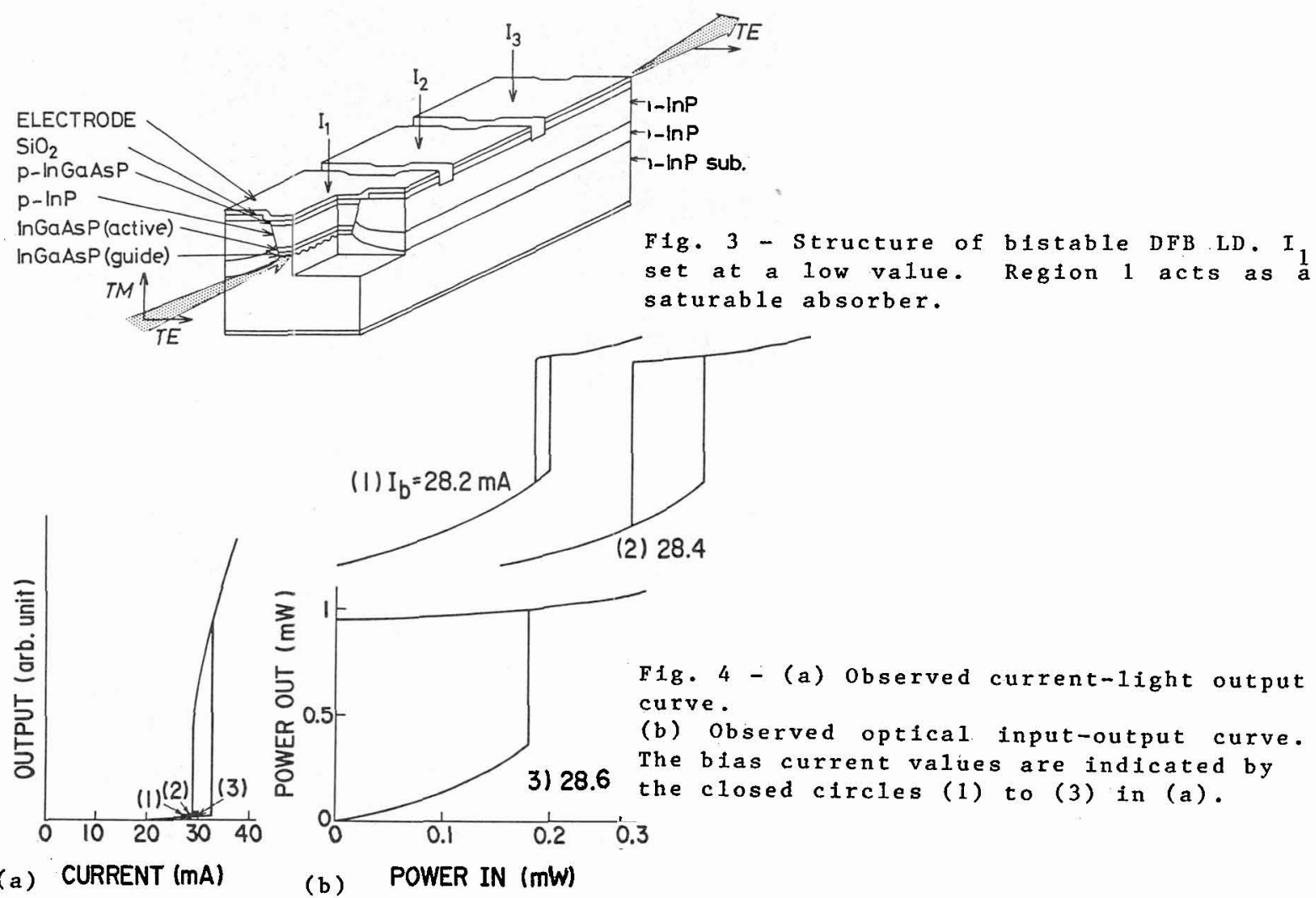

emits coherent light when input optical power is injected. The laser stays in an "ON state" even when the input optical power is reset at zero. This means that the bistable laser acts as an optical memory device.

Recently, a tunable optical-wavelength conversion device for photonic switching has been demonstrated using this same structure $/ 16 /$.

\section{Dispersive bistability}

A resonant type LD amplifier can act as a noniinear Fabry-Perot interferometer; and shows bistability. This is because the active layer refractive index changes due to gain saturation by light injection.

Among the many types of bistable semiconductor lasers studied previously, only Fabry-Perot type LD amplifiers appear to have multiple bistability or multistability potential. In the ID amplifier, there are many constructive interference transmission peaks. If cavity $Q$ stays constant, the device shows multistability. for strong light input intensities. However, cavity $Q$ decreases as the injected optical intensity is increased through gain saturation. Utilizing a long Fabry-Perot cavity LD amplifier, optical multiple bistability is demonstrated $/ 17 /$.

Let us consider the relationship between inputs and outputs for a resonant-type LD amplifier with two optical inputs /18/.

Using two optical inputs, a NAND gate and a NOR gate can be obtained. The Initial detuning of a signal beam is equal to $\pi$ radian, that $i s$, the signal beam wavelength coincides with the resonance wavelength of the LD amplifier when $P$ in = 0 . When $P$ is increased, carrier density decreases, causing the refractive Index of the active layer to become larger. This results in the lowertng of the 
cavity resonance frequency. Therefore, bistable characteristics are observed in

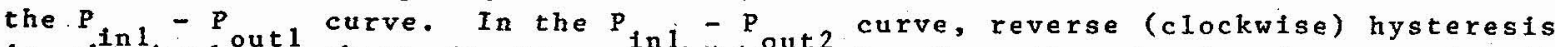
is obtained a as shown in Fig. inl(a) (1). on the other hand, when wavelength detuning of the signal beam from the resonance wavelength is greater than that of the control beam, normal (counterclockwise) hysteresises are observed in both the $P_{\text {In } 1}-P_{\text {out } 1}$, and the $P_{\text {in } 1}-P_{\text {out } 2}$ curves as shown in Fig. 5 (a)(ii).

The experimental results are shown in Fig. 5(b). In Fig. 5(i), the signal beam detuning is estimated to be $\pi$ radian from a comparison between the calculated and experimental results of the $P$ - P increastng the LD2 current, the wavelength of LD2 is shifted toward the longer wavelength side. In Fig. 5(il), a 2.2 radian signal beam detuning state is observed. Therefore, normal (counterclockwise) hysteresises are observed in both the $P$ - $P$, and the $P_{\text {in }}-P_{\text {put }}$ curves as shown in Fig. 5(ii). The experimentafnl resultst agree we11 with the theoretical results shown previousiy.

High speed switching has been demonstrated employing modulation of an $800 \mathrm{Mbit} / \mathrm{s}$ pulse pattern $/ 19 /$. In this experiment, the $\lambda_{2}$ input was kept constant, while the $\lambda_{1}$ input was directly modulated.

\section{Future Prospects}

Major remaining problems in bistable semiconductor lasers are the realization of two dimensional arrays and reduction in threhsold current.

Three types of surface-emitting bistable lasers have been proposed. Vertical
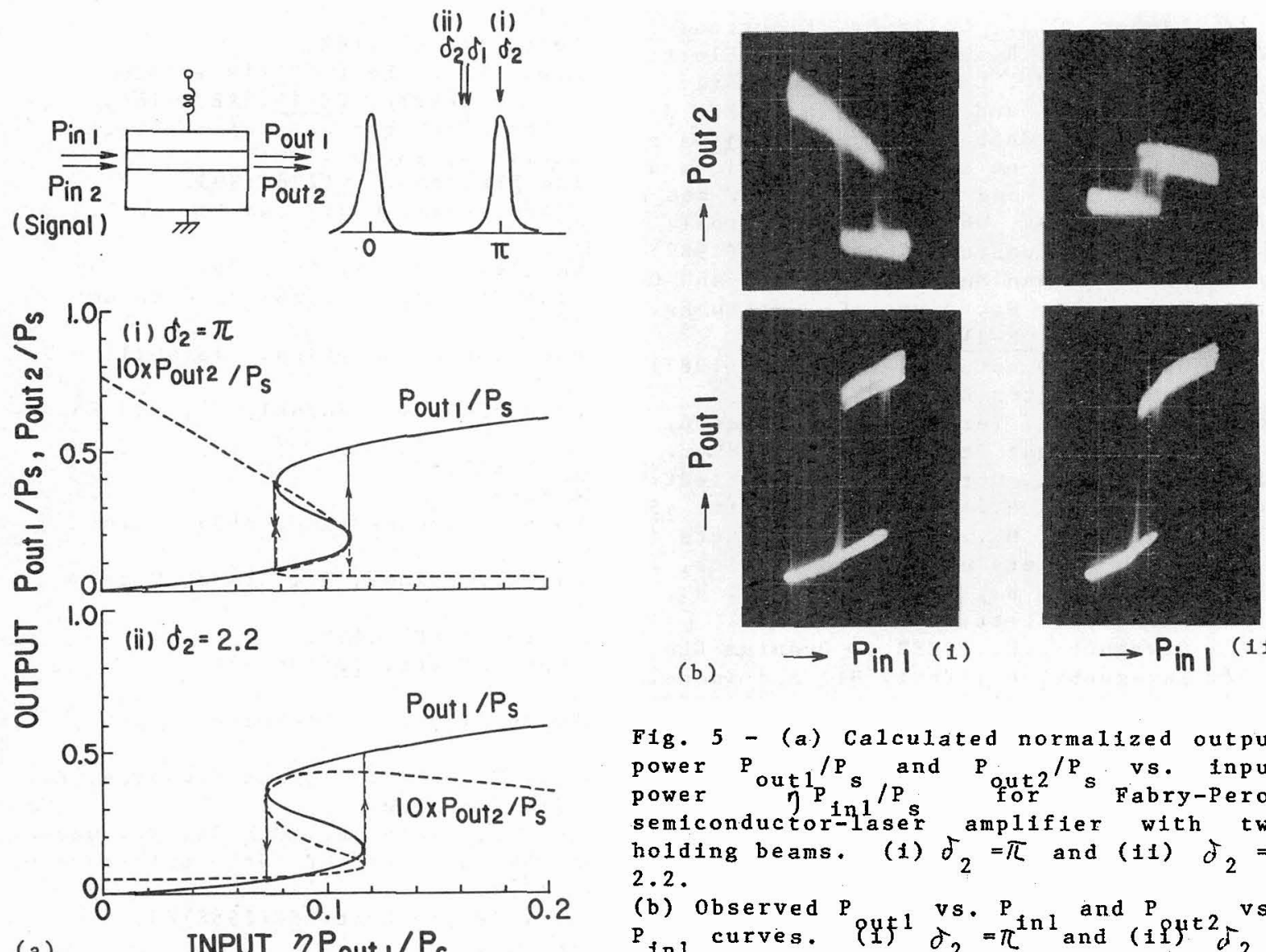
Fig. 5 - (a) Ca1culated normalized output power $P_{\text {out } 1 / P_{s} \text { and }} P_{\text {out } 2 / P_{s} \text { vs. input }}$

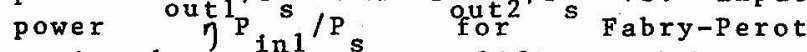 semiconductoriniaser amplifier with two holding beams. (i) $\delta_{2}=\pi$ and (ii) $\delta_{2}=$ 2.2 .

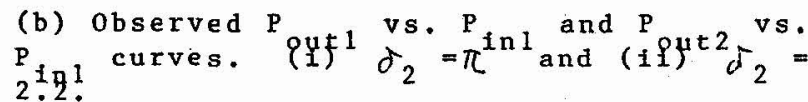


cavity-laser type optical logic and gate devices were proposed/20/ . These devices Include a saturable absorber in the vertical laser cavity. A surface emitting bistable LD using output coupling by second order grating of a distributed Bragg reflector $/ 21 /$ as well as the laser with an integrated beam deflector /22/ have also been demonstrated. However, the threshold currents of these devices are more than $50 \mathrm{~mA}$ at present. To construct two dimensional arrays, the threhsold currents have to be reduced.

Semiconductor lasers with threshold currents of less than 1 mA have been already reported. For example, a gallium-arsenide single-quantum-well, graded-index separate-confinement, buried-heterostructure laser has recently achieved a 0.55 mA threshold $/ 23 /$. It is believed using advanced technologies such as the quantum confined effects, LDs with a much lower threshold current, 1 pA threshold LDs, will be achieved /24/. In that case, construction of $1000 \times 1000$ two dimensional arrays may become possible in the future.

\section{Summary}

Recent progress in the study of absorptive and dispexsive bistability in semiconductor lasers was reported. The bistable semiconductor 1 asers will be advantageous in the fleld of transmission and exchange, utilizing the merits of optical gain. When threshold currents are reduced further, two-dimensional arrays of bistable LDs will become important in optical information processing.

\section{REFERENCES}

/1/ See also Kawagucht, H., Opt. and Quantum Electron. 19 (1987)S1.

/2/ Lasher, G.J., Solid-St. Flectron. 1(1964)707.

/3/ Kawaguchi, H. and Iwane, G., Electron. Lett. 17(1981)167.

/4/ Harder, CH., Lau, K.Y., and Yariv, A., Appl. Phys. Lett. 39(1981)382.

/5/ Otsuka, K, and Iwamura, H., IEEE J. Quantum Electron. oE-19(1983)1184.

16/ Mori, Y, Shibata, J., and Kajiwara, T, Extended abstracts of the $18 \mathrm{th}$ conference on solid state devices and materia1s, Tokyo (1986)723.

$17 /$ Chen, Y.C. and Liu, J.M., Opt. and Quantum Flectron. 19(1987) 593.

/8/ Maclean, D., White, I.H., Carrol1, J.E., Armistead, C.J., and Plumb, R.G., opt. and Quantum Electron. 19(1987) S103.

/9/ Glas, P. and Mu11er, R., Opt. and Quantum Electron. 14 (1982) 375 .

$110 /$ Kawaguchi, H., Inoue, K., Matsuoka, T., and Otsuka, K., IEEE J. Quantum ELectron. QE-21 (1985)1314.

$111 /$ opt. and Quantum Electron. 12(1987) Special Issue on optical B1stability in Semiconductor Lasers.

/12/ Suzuki, S., Terakado, T., Komatsu, K., Nagashima, K., Suzuki, $\Lambda$. , and Kondo, M., J. Ltght Tech. LT-4 (1986)894.

$/ 13 /$ Webb, R.P., Opt. and Quantum Electron. 19(1987)s57.

/14/ Kawaguchi, H., Appl. Phys. Lett. 45(1984) 1264 .

/15/ Kawaguchi, H., Extended Abstracts (The 45th Autumn Meeting, 1984). The Japan Society of Applied Physics, $13 a-R-2$.

$/ 16 /$ Kawaguchi, H., Oe, K, Yasaka, H., Magari, K., Fukuda, M., Itaya, Y., Electron. Lett. $23(1987) 1088$.

$117 /$ Kawaguchi, H., IEEE J. Quantum ELectron. QE-23 (1987)1429.

$/ 18 /$ Kawaguchi, H., Tani, H., and Inoue, K., optics Lett. 12(1987)513.

$/ 19 /$ Inoue, K., Electron. Lett. 23 (1987)921.

$120 /$ Nitta, J., Kolzumi, Y, and Iga, K., Cleo'86 Digest of Technical Papers, F04, San Francisco (1986)9.

/21/ Kojima, K., Kyuma, K., Noda, S., Mitsunaga, K., Ohta, J., and Hamanaka, K., Technical Report, IEICE(19B7) OQE87-68. (In Japanese)

$122 /$ Sugimoto, M., Hamao, N., Takado, N., Yeno, M., Iwata, H., Uchida, M., Onabe, K., Asakawa, K., and Yuasa, T., Extended abstracts of the 19 th conference on solid state devices and materials, Tokyo (1987) 523 .

$123 /$ Lau, K.Y., Darry, P.L., and Yariv, A., Appl. Phys. Lett. 52 (1988)88.

/24/ Yablonovitch, E., Phys, Rev. Lett. 58(1987)2059. 